\title{
Philosophical empathy (in the Style of Merleau-Ponty)
}

\author{
Matthew Ratcliffe ${ }^{1} \mathbb{C}$
}

Accepted: 2 February 2021 / Published online: 1 March 2021

(c) The Author(s) 2021

\begin{abstract}
Is there a sense in which we can be said to empathize with a philosophical position and, if so, what does empathy consist of here? Drawing on themes in the work of Maurice Merleau-Ponty, I sketch an account of the relationship between philosophical language and philosophical thought, according to which the task of understanding, evaluating, and building upon an explicit philosophical position can involve engaging with the experiential world of its author. If accepted, this account has broader implications for how we conceive of both empathy and philosophical thought.
\end{abstract}

Keywords Empathy $\cdot$ Indeterminacy $\cdot$ Language $\cdot$ Merleau-ponty $\cdot$ Possibility $\cdot$ Thought

\section{Introduction}

In this paper, I will sketch an account of what I call "philosophical empathy." One might take that term to concern any of the following: (a) empathizing with someone who happens to be a philosopher; (b) empathizing with that person as a philosopher, by attending specifically to her philosophical concerns; (c) empathizing in a philosophical way, by integrating philosophical knowledge and skill into an empathic process; (d) empathizing with a philosophical position. Achievement (a) is of little interest: if we can empathize with people in general, then we can empathize with people who happen to be philosophers. While (b) and (c) may well identify real and interesting phenomena, both require further clarification. However, it is tempting to dismiss (d) out of hand: there is no such thing as empathy with a philosophical position. Given that (d) might seem counter-intuitive, it is also of considerable interest if it does turn out to be a genuine phenomenon. In what follows, I will restrict my use of the term "philosophical empathy" to "empathy with a philosophical position" and will advance a conception of philosophical thought that accommodates this.

Matthew Ratcliffe

matthew.ratcliffe@york.ac.uk

1 Department of Philosophy, University of York, York, UK 
Why might philosophical empathy strike one as implausible? Suppose a position attributed to a specific philosopher is taken to consist in a series of interrelated propositions and arguments that can be evaluated by someone with appropriate knowledge and training, without any consideration of its author's psychology. Granted, we might seek to explain its origins or discredit it through psychological speculation, but we are not required to do so and, as good philosophers, we should refrain from ad hominem arguments. Philosophers have proposed various competing accounts of empathy and it is often hard to distinguish substantive disagreements from terminological disputes. Nevertheless, they at least share the assumption that empathy involves somehow engaging with the experiences of another individual. So, regardless of which account of empathy we endorse (or accounts, if we want to be pluralists), it seems that philosophical empathy is ruled out. The task of understanding another philosopher's experience is distinct from that of understanding and evaluating her explicit position.

In response, one could point out that we don't merely comprehend static philosophical positions. Philosophical understanding also involves appreciating patterns of philosophical thinking. And this, one might argue, involves "cognitive empathy."1 However, empathy concerns experience, and it might be objected that there is no characteristic phenomenology associated with propositional thought or its comprehension. So, what is further needed is the acknowledgement that thinking about $p$ or believing that $p$ does have a phenomenology, distinct from that of non-cognitive sensory experiences. ${ }^{2}$ It could then be maintained that empathizing with a philosophical position involves empathizing with the associated thought processes. But this still does not add up to (d). In coming to appreciate a philosophical position, I might well think through it and have a cognitive experience of the relevant propositions, but it remains my experience. When I further seek to understand the thoughts of another philosopher, I don't just engage in philosophical thinking myself in order to comprehend and evaluate her position; I perform an additional, separate act of cognitive empathy. What we have, if anything, is some combination of (b) and (c), rather than $(\mathrm{d})$.

In what follows, I will draw on the writings of Maurice Merleau-Ponty, in order to piece together an alternative approach, one that collapses the distinctions between (b), (c), and (d). I will focus on a strand of thought that runs through Phenomenology of Perception and various later works, including several of the essays collected in Signs and Sense and Non-Sense, as well as the incomplete manuscript The Prose of the World (set aside by Merleau-Ponty in 1952). Merleau-Ponty's thinking shifts in various ways over the course of these years. However, the themes I will emphasize appear consistently and together amount to a cohesive position. Although I will not offer a thorough defence of that position, I will at least suggest that it is coherent,

\footnotetext{
${ }^{1}$ The term "cognitive empathy" has been employed by several recent authors. For instance, Spaulding (2017, p.13) defines it as "the capacity to understand another person's state of mind from her perspective."

${ }^{2}$ See Bayne and Montague (2011) for a good overview of the current "cognitive phenomenology" debate.
} 
phenomenologically plausible, and worthy of further investigation. ${ }^{3}$ If broadly right, it has wider-ranging implications for how we conceive of empathy, nudging us away from the currently orthodox view that empathizing with another person is most centrally a matter of using one's own mind to "simulate" her experiences. It also amounts to a conception of what it is to think philosophically, use philosophical language, and understand philosophical positions.

\section{Understanding philosophers}

Across several works, Merleau-Ponty sketches a view of philosophical understanding that includes what I call "philosophical empathy." In this section, I will outline what I take that view to involve. Then, in the remainder of the discussion, I will relate it to differing conceptions of empathy. What I have in mind comes across most clearly and explicitly when Merleau-Ponty reflects on his relationship to Husserl. However, it is also a more general theme in his work. According to Merleau-Ponty, the tasks of understanding, criticizing, and further developing a philosophical position do not consist simply in grasping the meaning of what is written or said and then agreeing or disagreeing with it. His alternative is comprised of three interrelated claims, concerning (1) philosophical "style"; (2) idiosyncratic uses of written and spoken language, and (3) what Husserl calls the "horizonal" structure of experience. These claims are inextricable. While (1) and (2) may at first appear obscure and hard to pin down, they are illuminated by the inclusion of (3).

Starting with (1), Merleau-Ponty suggests that there is more to appreciating a philosophical position than comprehending the propositions that together comprise it. A philosophy also has a holistic style, a distinctive feel or atmosphere. This is something we may encounter before we have quite understood what is being claimed. A more specific, determinate apprehension of the philosopher's thought then takes shape. Finding one's way around a philosophical text is thus akin to immersing oneself in and exploring an unfamiliar place, which has an initial, inchoate feel to it. As Merleau-Ponty writes in Phenomenology of Perception:

And just as, when in a foreign country, I begin to understand the sense of words by their place in a context of action and by participating in everyday life, so too a philosophical text that remains poorly understood nevertheless reveals to me at least a certain "style"-whether Spinozistic, critical, or phenomenological-which is the first sketch of its sense. ${ }^{4}$

The nature of this elusive style and how a philosopher's position emerges out of it are inseparable from (2), idiosyncratic use of language. It is not enough to

\footnotetext{
${ }^{3}$ I do not want to suggest that the position outlined is to be found only in Merleau-Ponty. I am sure that aspects of it, or something much like it, can be drawn from other philosophers as well. I discuss MerleauPonty's writings in order to illustrate a way of thinking about philosophical thought and empathy, rather than taking him to be its sole advocate.

4 Merleau-Ponty (1945/2012, p. 184).
} 
understand the words in a generic way; one must also understand how that particular philosopher uses them. As with style, this involves coming to appreciate something holistic. It is not simply that a given philosopher uses specific terms in idiosyncratic ways; her uses hang together as a singular pattern or Gestalt and cannot be grasped independently of their interrelations. We begin by attributing established, generic meanings but gradually come to appreciate the subtle, distinctive, and interlocking ways in which words are employed, as the philosopher's distinctive style is progressively resolved. ${ }^{5}$

Both (1) and (2) can be made clearer by appealing to (3). Central to MerleauPonty's relationship to Husserl is a shared emphasis on how experience incorporates a sense of the possible and, with it, degrees of openness and indeterminacy. Consider Husserl's use of the term "horizon" to refer to structured systems of possibilities that are ubiquitous in human experience. ${ }^{6}$ When I look at a given entity, my sense of what it is and my sense that it is both depend on an experience of possibilities involving that entity. Husserl emphasizes interrelated sensorimotor possibilities, such as that of touching an entity that is seen, turning it around to view a hidden side, smelling it, and so forth. These experiences have an "if, then" structure. If I or someone else were to do something, or if something were to happen, then $x$ would be revealed to perception, where the content of $x$ (what is experienced as possible) is variably determinate: in turning around a cup, one might anticipate seeing a specific colour or just some colour or other. But no perceptual experience involves a fully determinate grasp of every potential perception involving a given entity; there is always some degree of openness and indeterminacy.

Horizons do not adhere to individual entities in isolation from a wider environment; experience as a whole has a cohesive horizonal structure. This structure is bound up with our bodily phenomenology. For the most part, experienced possibilities consist in the anticipation of what will happen when we act upon the perceived environment. Hence, they are inextricable from a sense of our bodily capacities and dispositions. Felt bodily dispositions to engage in perceptual activities are, at the same time, salient possibilities that we experience as residing in perceived entities. ${ }^{7}$

Merleau-Ponty indicates that what applies to sensory perception of our surroundings applies equally to the perception of spoken and written language. Words, sentences, and relations between them are not uttered and written in isolation from our wider engagement with a world of possibilities but entwined with our practice. Like perceived objects, they have what Husserl calls a "horizonal" structure. For the most part, the horizon of a familiar entity such as a drinking glass is shaped by habitual activities involving that entity and/or entities of its type. Consequently, the possibilities experienced as adhering to it are fixed and unwavering. Likewise, the possibilities that attach to utterances (which point both to other utterances and to nonlinguistic aspects of practice) are fixed largely by convention-by shared habit and consensus. Nevertheless, when speaking and writing, our words sometimes deviate

\footnotetext{
5 e.g. Merleau-Ponty (1964c, p. 91).

6 e.g. Husserl (1952/1989).

7 Ratcliffe (2015, Ch. 2).
} 
from these conventions and point to novel arrangements. A familiar entity taken out of context or an unfamiliar entity placed in a familiar context can be encountered in terms of possibilities that differ from the norm, in ways that are often experienced as disruptive. Likewise, a work of art can combine habitual meanings with something incongruous, shaking up and-in so doing-making explicit practical meanings that are more usually taken for granted. In a similar way, a philosopher's distinctive style can be construed as a cohesive horizonal structure that is to some degree idiosyncratic, deviating from established arrangements of possibilities while evoking new ones. $^{8}$

Merleau-Ponty states explicitly that we encounter linguistic possibilities in a way that resembles practically engaged perceptual experience. Skilful, perceptual activity involves coming to adopt an optimal orientation relative to an object of perception, through which possibilities are resolved and integrated so as to reveal it as what it is. Similarly, we strive to relate to a philosophical text in a way that provides optimal resolution, where its possibilities coalesce into a distinctive, unambiguous arrangement:

Even though only Abschattungen of the signification are given thematically, the fact is that once a certain point in discourse has been passed the Abschattungen, caught up in the movement of discourse outside of which they are nothing, suddenly contract into a single signification. And then we feel that something has been said-just as we perceive a thing once a minimum of sensory messages has been exceeded. ${ }^{9}$

This is not to be construed in terms of rendering something fully determinate. Even when language is resolved in this way, a philosophical position, whether spoken or written, continues to point beyond itself. In the same way that perceived objects are "inexhaustible, never entirely given," "what is expressed is never completely expressed." ${ }^{10}$ In comprehending it, we do not simply glue together the fixed, exhaustive meanings attaching to however many words and sentences. We continue

\footnotetext{
${ }^{8}$ There is more to be said about what, exactly, these possibilities adhere to and how they should be integrated into a broader account of linguistic meaning. They do not depend on some quality of perceived speech, as they are also integral to our experiences of written texts. Hearing and reading a word are analogous to encountering the same entity through sight and touch. As Edie (1976, p. 88) observes, quoting from Phenomenology of Perception, "words carry, beneath their conceptual meanings and forms, an 'immanent' 'existential meaning', which is not merely rendered by them but which 'inhabits them'." This is what $\mathrm{I}$ have suggested we think of in terms of a horizonal structure attaching to perceptual experiences of written and spoken words. There is also a great deal more to say about the kinds of possibilities that are integral to our experiences of written and spoken language (what it is that we experience as possible) and how these possibilities relate to, influence, and are influenced by our wider experience of the world.

9 Merleau-Ponty (1964a, p. 91). The term "maximum grip" is often used to refer to Merleau-Ponty's conception of how we pre-reflectively position ourselves to achieve an optimal vantage point for perceiving something (Merleau-Ponty 1945/2012, Part Two, Ch. 3). We could similarly speak of "linguistic maximum grip," a dynamic, progressive way of orienting ourselves towards another person's language, such that we are better placed to resolve its holistic, idiosyncratic possibilities.

10 Merleau-Ponty (1973, p. 37).
} 
to engage with possibilities that are to some degree indeterminate, even after the position has coalesced out of an initially nebulous style.

The incompleteness is not exclusively epistemic; a philosophy does not remain indeterminate only because one does not know someone else's thoughts in their entirety. As with perceptual experience, there are degrees of indeterminacy in the first-person case too. Although we have some sense of where our thoughts are taking us, their destination often remains hazy; we only recognize where exactly we were heading when we have arrived there. And completion is not solely a first-person matter; it is not restricted to the progression of one's own thought. When contemplating the work of another philosopher, we may similarly actualize possibilities inherent in it, sometimes in ways that the author did not foresee or even could not have foreseen. This is how Merleau-Ponty construes his debt to Husserl:

At the end of Husserl's life there is an unthought-of element in his works which is wholly his and yet opens out on something else. To think is not to possess the objects of thought; it is to use them to mark out a realm to think about which we therefore are not yet thinking about. ${ }^{11}$

Merleau-Ponty proceeds to "evoke this unthought-of element in Husserl's thought," to actualize possibilities that are there, inherent in Husserl's thinking although not explicitly recognized by Husserl. ${ }^{12}$ To inhabit a system of philosophical possibilities in this way is not to duplicate them, but to embark on paths towards which they point. As Merleau-Ponty acknowledges, our ability to do so is constrained by circumstances, including the nature and extent of our relationship to the thinker in question. We invariably encounter a philosophy from a partial perspective, one of many potential vantage points.

To appreciate how this adds up to a kind of empathy, another aspect of MerleauPonty's philosophy needs to be introduced. When we write and speak, in philosophical contexts and more widely, a clear line cannot be drawn between language and thought; the two are inextricable. ${ }^{13}$ The relationship between them is much like that between an emotion and its expression. In both cases, one does not arise first, in its entirety, and only then cause the other-at least not always. There is a tendency within an emotional feeling towards its expression. Furthermore, the expression can be partly constitutive of the emotion-it completes it rather than follows it. Expressive completion can render an emotional experience more determinate, even making it the kind of experience it is. ${ }^{14}$ Sometimes, it is only by expressing my anger that I come to realize it is anger that I feel, that I am angry with you, that I am angry about what you did. Similarly, a thought is not an inner entity that is fully formed and only

\footnotetext{
11 Merleau-Ponty (1964a, p. 160).

12 Merleau-Ponty (1964a, p. 160).

13 Merleau-Ponty 1945/2012, Part One, VI).

14 See Colombetti (2009) for an interesting discussion of ways in which the "expression" of an emotion and, more specifically, its linguistic expression, can be partly constitutive of that emotion. See also Ratcliffe (2017, Ch. 4) for discussion of how linguistic expression can render emotional experiences more determinate.
} 
afterwards converted into language. Prior to its expression, it is not something that can be introspected and pinned down precisely:

Thought is nothing "inner," nor does it exist outside the world and outside of words. What tricks us here, what makes us believe in a thought that could exist for itself prior to expression, are the already constituted and already expressed thoughts that we can silently recall to ourselves and by which we give ourselves the illusion of an inner life. But in fact, this supposed silence is buzzing with words-this inner life is an inner language. ${ }^{15}$

A philosopher's thinking is not wholly hidden inside a head from which words emanate. Where it might seem so, this is attributable to the activity of inner speech. Like speaking and writing, inner speech is partly constitutive of thinking, contributing to the generation and actualization of possibilities. However, spoken and written language are not always preceded by fully formed inner speech. Hence, by engaging with the distinctive horizonal structure of a person's words, we may also encounter something of her thinking, including how it points to certain possibilities in a cohesive, non-accidental, but not fully explicit way. We do not "get inside someone's head," coming to experience her possibilities in much the same way she currently does or once did. Rather, our own distinctive perspective is retained throughout-we follow paths that she would not have followed and actualize possibilities that her thought pointed to but of which she was not yet explicitly aware. We don't discover a static, fully determinate inner life but a direction that is neither straightforwardly present nor absent.

Now, even if some of this is accepted, it is not plausible as a phenomenological account of what one experiences when wading through the latest articles in a professional journal that one feels obliged to consult. However, we can appeal here to a contrast drawn by Merleau-Ponty between original or authentic and institutionalized language. He suggests that much of what we say and write is dictated largely by convention, running along familiar paths laid out by habitual, shared norms. Our words are imbued only with the usual, generic possibilities:

We live in a world where speech is already instituted. We possess in ourselves already formed significations for all these banal words [paroles]. They only give rise in us to second-order thoughts, which are in turn translated into other words that require no genuine effort of expression from us, and that will demand no effort of comprehension from our listeners. ${ }^{16}$

This is to be contrasted with a speech that evokes new possibilities, enabling one to say and think what could not be said or thought before. In Phenomenology of Perception, Merleau-Ponty distinguishes between "languages" (langages) and "speech" (parole). While language is fixed by layers of "sedimented" habit, speech brings words together in ways that generate new possibilities for experience and thought. ${ }^{17}$

15 Merleau-Ponty (1945/2012, pp. 188-9).

16 Merleau-Ponty (1945/2012, p. 189).

17 Merleau-Ponty (1945/2012, p. 202). 
In later works, he develops this distinction in new ways by drawing heavily on his interpretation of Saussure. ${ }^{18}$

Returning again to the structural parallels between language and perception, it might appear to naïve reflection that perceptual experience simply reveals the ingredients of a stable, fully determinate world. But this involves failing to acknowledge how seemingly straightforward perceptual achievements are indebted to a history of habitual activities and associated patterns of expectation. In short, the achievement of having an experiential world at all, a pre-reflective backdrop to perception, action, and thought, is overlooked. In the same way, Merleau-Ponty suggests that "the clarity of language is in fact established against an obscure background." ${ }^{19}$ Linguistic meanings might seem stable, determinate, fully shared, and unproblematic, but only because we fail to recognize the prior phenomenological accomplishment of having a world within which conventional language is embedded and follows established trails. However, there is also authentic language, which reveals new possibilities, harbouring the potential to expose the ordinarily taken-for-granted world as a contingent accomplishment. A "sedimented" language is thus contrasted with the potential to generate novel meanings and thoughts:

One can have no idea of the power of language until one has taken stock of that working or constitutive language which emerges when the constituted language, suddenly off centre and out of equilibrium, reorganizes itself to teach the reader - and even the author - what he never knew how to think or say. ${ }^{20}$

It would be wrong to construe this as a simple contrast between good and bad language, even if we limit ourselves to the practice of philosophy. Sedimented language is integral to having a world and is therefore required in order to think and speak at all. Authentic speech involves a disturbance of that world and could not arise without there being something to disturb. Merleau-Ponty's conception of how we understand another philosopher is inextricable from his conception of what philosophy (and, more specifically, phenomenology) is. It is concerned with acknowledging and articulating a world more usually presupposed, a world that hides behind the obvious: "Philosophy is not a particular body of knowledge; it is the vigilance which does not let us forget the source of all knowledge." 21 Philosophy involves gaining some insight into what is more usually overlooked, and disturbances of the possible are integral to that process. Thus, what we have is a conception of philosophical inquiry that encompasses language, thought, and our wider relationship with the

\footnotetext{
18 e.g. Merleau-Ponty (1973, Ch. 2). For a good discussion of of how Merleau-Ponty interprets and draws upon Saussure, see Andén (2018). For a wider-ranging discussion of Merleau-Ponty on language, see Edie (1976).

19 Merleau-Ponty (1945/2012, p. 194).

20 Merleau-Ponty (1973, p. 14).

21 Merleau-Ponty (1964a, p. 110).
} 
world. ${ }^{22}$ It is something that Merleau-Ponty both describes and, at the same time, enacts through his own distinctive style.

I will now suggest that, if something like this is admitted as part of the philosophical enterprise, then engaging adequately with a philosophical position (one that is original in a certain kind of way) requires empathy. Without it, we might still be able to describe, discuss, and criticize another philosopher's work, but we would miss something important-an idiosyncratic system of indeterminate possibilities. There are also implications here for our understanding of what empathy is and what it is not.

\section{Empathy?}

According to some philosophers in the phenomenological tradition, including Edmund Husserl and Edith Stein, empathy (Einfühlung) is a quasi-perceptual achievement, which comprises our most basic sense of others as subjects of experience and also provides more specific insights into what they are experiencing. ${ }^{23} \mathrm{We}$ do not have to experience someone's words in order to recognize that person as a subject of experience. Nevertheless, Merleau-Ponty's conception of our engagement with written and spoken language can be integrated into a broader conception of empathy as somehow perceptual or perception-like. The point to emphasize is that expressions are not secondary to but integral to emotions and thoughts. For Merleau-Ponty, experiencing someone's expression of emotion or thought is analogous to having a perspective upon a perceived object, which points to possibilities for further experiences involving that object and therefore includes a much richer (but still incomplete) grasp of it. Similarly, the thought or feeling is not hidden behind the perceived expression or gesture but inseparable from the possibilities with which it is imbued.

In this manner, authentic speech (including writing) is inseparable from thought. As Merleau-Ponty writes, "reading projects us beyond our own thoughts toward the other person's intention and meaning, just as perception takes us to things themselves across a perspective of which we become aware only after the event." ${ }^{24}$ Perception of experience in expression and our engagement with language thus have a

\footnotetext{
22 Heidegger, in his 1929-30 lecture course The Fundamental Concepts of Metaphysics, draws a complementary distinction between genuine philosophizing and practices of proposition-hurling that remain embedded in conventional language: "a dialogue that is a philosophizing is rarely or never at all attained among those who busy themselves with philosophy, yet do not philosophize. So long as this elementary readiness for the intrinsic perilousness of philosophy is lacking, a confrontation that is a philosophizing will never occur, no matter how many articles are launched against one another in journals" (Heidegger 1995, p. 20). However, we should be wary of endorsing simple contrasts between authentic and institutionalized modes of philosophical inquiry. Philosophical thought plausibly has many different roles to fulfill and spans many different techniques. What I am concerned with here is one conception of one kind of philosophy. I do not want to suggest that any forms of philosophy to which "philosophical empathy" is either inapplicable or less applicable are somehow superficial or otherwise inferior.

23 see, e.g., Zahavi (2001, 2010, 2014).

24 Merleau-Ponty $(1973,14)$.
} 
common structure. In many instances, the two are also inextricable. Hence, Merleau-Ponty's account of language and thought can be grafted onto an account of empathy as second-person, perceptual or perception-like experience. This substantially extends the reach of empathy, the kinds of cognitive achievements that are amenable to empathic access.

In contrast, Merleau-Ponty's approach is incompatible with current philosophical orthodoxy, which takes empathy to consist, most centrally, in one or another form of simulation. ${ }^{25}$ Empathy, it is claimed, involves generating a first-person copy of someone else's experience. To qualify as empathy, the simulation must also be caused in an appropriate way and the relevant experience must be attributed to the other person. A distinction is often drawn between implicit and explicit empathy/ simulation. The former involves effortlessly generating a perception-like experience of someone else's mental life through a non-conscious simulation process, whereas the latter involves conscious, effortful replication of mental states. For example, Goldman contrasts non-conscious "mirroring" with "reconstructive" empathy, while Stueber distinguishes between "basic" and "reenactive" empathy. ${ }^{26}$ There is a further distinction to be drawn between two conceptions of explicit simulation. Empathy could be taken to involve appreciating how you would feel when placed in someone else's situation. However, others insist that it requires something more demanding than this: an appreciation of what it is like for her to be in that situation, which may well differ from what you would experience. For instance, Coplan proposes that empathy is a matter of "other-oriented perspective-taking" rather than just putting oneself in another person's situation. ${ }^{27}$

None of these achievements capture what Merleau-Ponty describes. Could you come to understand another person's philosophical thinking by replicating it and then attributing it to her? If Merleau-Ponty is right, the answer is no. For a start, the task would be too psychologically demanding. Philosophical, artistic, and literary works are entwined in various intricate ways with the lives of their authors. This is evident from Merleau-Ponty's description of Cézanne, where he states that a life is not determined by its work or vice versa, but that the two are, nonetheless, inseparable:

Although it is certain that a man's life does not explain his work, it is equally certain that the two are connected. The truth is that this work to be done called for this life. From the very start, the only equilibrium in Cézanne's life came from the support of his future work. The work to come is hinted at, but it would be wrong to take these hints for causes, although they do make a single adventure of his life and work. ${ }^{28}$

What does this "single adventure" amount to? A life and a philosophy share a common structure, the latter being integral to the former. That structure consists in a

\footnotetext{
25 e.g. Goldman (2006), Stueber (2006), Coplan (2011).

26 Goldman (2011); Stueber (2006).

27 Coplan (2011).

28 Merleau-Ponty (1964b, p. 20).
} 
cohesive engagement with possibilities, something that is habitually sculpted (where the possibilities comprising a philosophy and those comprising a more general life can relate to one another in a number of different ways). Grasping a person's philosophy does not differ qualitatively from getting to know him; it is just more specifically focused. We detect a style that pervades and binds together the person's behaviour, where word and thought relate to one another in much the same manner as body and soul:

[...] just as a man's body and "soul" are but two aspects of his way of being in the world, so the word and the thought it indicates should not be considered two externally related terms: the word bears its meaning in the same way that the body incarnates a manner of behaviour. ${ }^{29}$

In line with criticisms that others have levelled against simulation, it is plausible to insist that a holistic engagement with the possible cannot be replicated in the first-person. Peter Goldie distinguishes "empathetic perspective-shifting" from what he calls "in-his-shoes perspective-shifting," where only the former involves grasping how things are for someone else ${ }^{30}$ Goldie argues that empathetic perspectiveshifting only works in very simple, straightforward cases, where almost everything can be taken for granted as shared. When required to simulate the likes of character, personality, habits, abilities, and moods, we encounter a problem: it is often the case that they only contribute to a person's experience in the manner they do if they remain in the experiential background. However, they cannot do so when featuring in an explicit simulation: one can only input the relevant data explicitly and this inevitably distorts what one seeks to replicate. Experience has a foreground/background structure, which must be respected if a simulation is to succeed, but cannot be respected if the simulation is explicit. Thus, where a philosophy is holistic, idiosyncratic, and embedded in a life, we do not come to empathize with it via explicit simulation. Instead of engaging with novel possibilities, we would end up imposing our own possibilities upon it.

This leads into a further concern, which applies not only to empathetic perspective-shifting but to all forms of explicit and implicit simulation. To encounter an experience as the experience of another person is to engage with possibilities that are integral to it. This cannot be a matter of replicating the other person's perspective, as one's insight into the relevant possibilities differs from hers. What is implicit in her experience might be explicitly laid out for me; I might see paths to follow that she does not; I might also draw those paths to her attention, revealing new possibilities for her as well. So, there is a structural difference between first- and secondperson experiences of possibility, which remains in place throughout the process. Furthermore, experience is dynamic and incomplete; one cannot capture a pure, unadulterated, synchronic experience in its entirety. As Slaby points out, experiences

\footnotetext{
29 Merleau-Ponty (1964b, p. 53).

30 Goldie (2011).
} 
are not atomistic "inner objects" to be duplicated, contrary to the images that talk of "simulating experiences" might conjure up. ${ }^{31}$

One objection to the view I have sketched here is that understanding a type of philosophical position need not involve attributing it to anyone in particular. Therefore, empathy with its author cannot play a role in its comprehension. However, we can respond to this by re-emphasizing Merleau-Ponty's contrast between original and conventional modes of linguistic expression. Philosophical empathy is compatible with typifying the work of others. As you feel your way into a philosophical text, you may at first recognize a certain type of position or approach. But you do not have to stop there. In any instance where an author uses language in a distinctive, idiosyncratic way, so as to move beyond philosophical convention, there is the prospect of zooming in more closely, to experience something of that individual's thought. If Merleau-Ponty is right, and if I am right about Merleau-Ponty, this is not a matter of postulating underlying psychological causes but of experiencing a cohesive orientation towards the possible, in a way that is inseparable from comprehending an explicit philosophical position.

\section{Therapeutic empathy}

I do not want to rule out the possibility of simulating certain "philosophical" aspects of experience and, in the process, somehow contributing to philosophical understanding. I have suggested, though, that philosophical empathy cannot consist principally in simulation. However, there is a more illuminating comparison to be drawn between philosophical empathy and certain accounts of how empathy operates in clinical and therapeutic contexts. Take, for instance, Carl Rogers' conception of empathy. In earlier work, Rogers sometimes describes empathy in ways that might be taken to suggest simulation. ${ }^{32}$ However, drawing inspiration from work by Eugene Gendlin, he later comes to characterize it as a collaborative, dialogical process-a way of relating to someone that renders one attentive to the flow of her experience:

The way of being with another person which is termed empathic has several facets. It means entering the private perceptual world of the other and becoming thoroughly at home in it. It involves being sensitive, moment to moment, to the changing felt meanings which flow in this other person, to the fear or rage or tenderness or confusion or whatever, that he/she is experiencing. It means temporarily living in his/her life, moving about in it delicately without making judgments, sensing meanings of which he/she is scarcely aware, but not trying to uncover feelings of which the person is totally unaware, since this would be too threatening. It includes communicating your sensings of his/ her world as you look with fresh and unfrightened eyes at elements of which

${ }^{31}$ Slaby (2014).

${ }^{32}$ But for an alternative interpretation, see Ratcliffe (2018). 
the individual is fearful. It means frequently checking with him/her as to the accuracy of your sensings, and being guided by the responses you receive. You are a confident companion to the person in his/her inner world. By pointing to the possible meanings in the flow of his/her experiencing you help the person to focus on this useful type of referent, to experience the meanings more fully, and to move forward in the experiencing. ${ }^{33}$

"Entering" a world in this way is quite different from simulating it. Returning to Merleau-Ponty on style, it is more like entering an unfamiliar place and experiencing an inchoate atmosphere out of which more determinate arrangements take shape. The therapist adopts the role of companion rather than duplicate. Her perspective differs essentially from that of the client, allowing her to make explicit and reshape certain "meanings" by participating in a collaborative process. With this, Rogers recognizes the importance of indeterminacy-the ways in which a therapist may respond to possibilities that are "there" but not fully recognized by the client.

Various others who describe clinical or therapeutic empathy identify similar themes, rather than taking simulation to be central. For example, Jodi Halpern stresses "curiosity about and attunement to the patient's predicament," along with an "openness to learning something new." With this, the empathizer is able to engage with experience in a way that enables the client to "expand" and "recontextualize" ideas. ${ }^{34}$ Alfred Margulies explicitly acknowledges the incompleteness of experience and how empathic interactions facilitate actualization and transformation of possibilities: "Possibilities are what we reveal or even create; we feel into an aspect of the person that does not yet fully exist. Our patients follow us into that potential aspect of themselves: They feel into their possibilities for themselves." 35 Again, the task is not to duplicate the client's world, but to experience and interact with its possibilities.

An important difference between therapeutic interaction and Merleau-Ponty's relationship with Husserl is that the former involves a dialogical process. In contrast, relating to Husserl is one-sided; Husserl cannot respond by correcting MerleauPonty's reading or by pointing to alternative paths. However, the difference here is not qualitative but one of degree. As Merleau-Ponty concedes from the outset, his access to Husserl's thought is limited. We might think of the relationship in terms of incomplete or unreciprocated empathy, rather than something altogether different from what Rogers and others describe. It can be added that, in many other instances, philosophical dialogue is indeed possible, along with experiences of reciprocity and mutual enlightenment.

The position I have attributed to Merleau-Ponty is, in my view, a coherent one. But is it also plausible? It is difficult to formulate a straightforward argument on its behalf. If Merleau-Ponty is right, then a broad philosophical orientation of this kind is something one comes to appreciate by inhabiting it and developing a feel

\footnotetext{
33 Rogers (1975, p. 4). See also Gendlin (1962).

34 Halpern (2001, xi-xii; p. 41).

35 Margulies (1989, p. 131).
} 
for it. One cannot be pushed towards it in a reliable way through the force of one or another explicit argument. Nevertheless, the account I have sketched does help to illuminate a range of phenomena that we encounter over the course of our intellectual lives. And this counts in its favour, at least where alternative approaches fail to illuminate or even to acknowledge the phenomena in question.

Take the claim that spoken and written philosophical positions are permeated by indeterminate possibilities, pointing in directions that can then be followed. This perhaps captures the way in which many of us understand and develop our own work over the course of time. For example, here is Stanley Cavell, reflecting on the relationships between his early and later works:

But I understand the presence of notable, surprising anticipations to suggest something more specific about the way, or space within which, I work, which I can put negatively as occurring within the knowledge that I never get things right, or let's rather say, see them through, the first time, causing my efforts perpetually to leave things so that they can be, and ask to be, returned to. Put positively, it is the knowledge that philosophical ideas reveal their good only in stages, and it is not clear whether a later stage will seem to be going forward or turning around or stopping, learning to find oneself at a loss. ${ }^{36}$

Our ideas, at least those that continue to concern us, point in directions that may be hazy. Feelings of tension, incompleteness, and even urgency can push us in those directions: something must be resolved, completed-it cannot be left as it is. This can apply both to one's own past work and to one's engagement with others' work. Similarly, during those moments when we feel understood by another philosopher, the experience plausibly consists not so much in someone else seeming to have the same ideas, but in having our thoughts followed up, completed, built upon, and steered in novel directions.

Merleau-Ponty's approach is not only consistent with his own linguistic portraits of various thinkers. We can also find complementary themes in descriptions that others have offered of philosophers and their work. For example, take this excerpt from an obituary for the philosopher Bernard Williams (1929-2003):

Dazzlingly quick and devastating in discussion, he was famously able to summarise other people's arguments better than they could themselves, and anticipate an antagonist's objections to his objections-and, in turn, his objections to hers before she had even finished her sentence. Utterly rigorous, yet wonderfully non-academic, his philosophy is permeated by a distinctive philosophical voice-witty, erudite and humane-and by a sense of his own humorous and tragic view of life. He always, as one of his devoted ex-students observed, did philosophy as a whole human being. ${ }^{37}$

\footnotetext{
36 Cavell (2002, xvii).

37 https://www.theguardian.com/news/2003/jun/13/guardianobituaries.obituaries (last accessed 4th January 2021).
} 
Merleau-Ponty provides an account of what it is for a philosophy to have a distinctive "voice," how it is done by a "whole human being," what it is to anticipate a thought before it has even been articulated, and how someone else might have a better grasp of one's position than oneself. Nevertheless, there is the lingering worry that we can just as well comprehend propositions and criticize philosophical positions without having any empathic feel for them. So, even if philosophical empathy is a real phenomenon, it is inessential to inquiry. No doubt, much philosophical work can and does proceed without it. However, this does not apply to any philosophy that seeks to reflect upon a world we more usually inhabit comfortably and overlook. For Merleau-Ponty, a philosophy cannot escape convention without going beyond conventional language. And, if one cannot see past convention, one cannot reflect upon the phenomenological achievements that it both presupposes and obscures. Philosophy of that nature cannot be done unless one uses language to shake up what is ordinarily presupposed, to generate new possibilities that others may then engage with. I take this to be integral to Merleau-Ponty's conception of the "phenomenological reduction," something that is invariably partial and requires a "loosening" of what binds us to the world, thus illuminating phenomenological achievements that are more usually obscured. ${ }^{38}$

The broader view that experiencing other subjects of experience essentially involves a sense of possibility, indeterminacy, and incompleteness is also phenomenologically defensible. One way to develop a case for it is to examine various scenarios where this sense of the possible is diminished or absent from an interpersonal encounter. Here are two candidates:

An Open Book. In the book Lived Time, Eugene Minkowski describes interacting with a particular patient and having a distinctive feeling, which is expressed linguistically as "I know all about him." This feeling involves an experience of the patient as lacking something profound, which impedes the ability to experience and relate to him as an experiential subject. Reflecting on the nature of the impairment, Minkowski concludes that his own feelings of strangeness and privation originate in the patient's experience of time, which lacks a more usual orientation towards the future, involving the structured, purposive actualization of possibilities. In relating to someone whose world is no longer imbued with this sense of open possibility, there is "the impression, in listening to the patient speak, of being constrained to read an open book, as if there were nothing behind the pages of that book." 39

Losing Her Twice. In his memoir of bereavement, A Grief Observed, C. S. Lewis describes the experience of losing his wife a second time. In striving to preserve her in his memory, all he succeeds in retaining is his own image of her. He asks, "won't the composition inevitably become more and more my own?" What is missing is any sense of her as a locus of possibility, distinct from his own conception: "The reality is no longer there to check me, to pull me up short, as the real H. so often did, so unexpectedly, by being so thoroughly herself and not me." One's sense of a particular person cannot endure by being fixed in memory; whatever image one

38 Merleau-Ponty (1945/2012, lxxvii).

39 Minkowski (1970, pp. 176-9). 
preserves will impose one's own possibilities, silencing hers. Later, Lewis writes that it is only when he ceased in his preservation-efforts that he "remembered her best," not as a "memory" but as an "instantaneous, unanswerable impression." 40

A common theme of these two examples is that experiencing someone as a unique locus of experience involves recognizing and responding to her possibilities, rather than comprehending or even simulating however many psychological properties or entities that either are or were encased inside her skull. A spoken or written philosophy may be experienced similarly as alive or dead, present or distant. When a philosophy "lives," there is a self-affecting experience of its possibilities. And this, I have suggested, amounts to a kind of empathy. It is not, however, something that is exclusive to explicitly philosophical thought. Although inseparable from phenomenological method (as conceived of by Merleau-Ponty), it also informs our interactions with art, literature, and other media. The common ingredient is an experience of feeling-in (Einfühlung), which can be illuminated by examining the phenomenology of possibility, while at the same time resisting firm distinctions between thought and its linguistic expression.

Acknowledgements Thanks to the Phenomenology Reading Group at the University of York and an audience at University College Dublin for helpful comments and suggestions.

Open Access This article is licensed under a Creative Commons Attribution 4.0 International License, which permits use, sharing, adaptation, distribution and reproduction in any medium or format, as long as you give appropriate credit to the original author(s) and the source, provide a link to the Creative Commons licence, and indicate if changes were made. The images or other third party material in this article are included in the article's Creative Commons licence, unless indicated otherwise in a credit line to the material. If material is not included in the article's Creative Commons licence and your intended use is not permitted by statutory regulation or exceeds the permitted use, you will need to obtain permission directly from the copyright holder. To view a copy of this licence, visit http://creativecommons.org/licen ses/by/4.0/.

\section{References}

Andén, L. 2018. Language and tradition in Merleau-Ponty's reading of Husserl and Saussure. Studia Phaenomenologica 18: 183-205.

Bayne, T., and M. Montague, eds. 2011. Cognitive phenomenology. Oxford: Oxford University Press.

Cavell, S. 2002. Must we mean what we say? Updated. Cambridge: Cambridge University Press.

Colombetti, G. 2009. What language does to feelings. Journal of Consciousness Studies 16: 4-26.

Coplan, A. 2011. Will the real empathy stand up? A case for a narrow conceptualization. The Southern Journal of Philosophy, Spindel Supplement 49: 40-65.

Edie, J.M. 1976. Speaking and meaning: The phenomenology of language. Bloomington: Indiana University Press.

Gendlin, E.T. 1962. Experiencing and the creation of meaning. New York: Free Press of Glencoe.

Goldie, P. 2011. Anti-empathy. In Empathy: Philosophical and psychological perspectives, ed. A. Coplan and P. Goldie, 302-317. Oxford: Oxford University Press.

Goldman, A. 2006. Simulating minds: The philosophy, psychology and neuroscience of mindreading. Oxford: Oxford University Press.

${ }^{40}$ Lewis (1966, p. 17; p. 39). 
Goldman, A. 2011. Two routes to empathy: Insights from cognitive neuroscience. In Empathy: Philosophical and psychological perspectives, ed. A. Coplan and P. Goldie, 31-44. Oxford: Oxford University Press.

Halpern, J. 2001. From detached concern to empathy. Oxford: Oxford University Press.

Heidegger, M. 1983/1995. The fundamental concepts of metaphysics, trans. W. McNeill and N. Walker. Bloomington: Indiana University Press.

Husserl, E. Ideas pertaining to a pure phenomenology and to a phenomenological philosophy: Second book, trans. R. Rojcewicz and A. Schuwer. Dordrecht: Kluwer.

Lewis, C.S. 1966. A grief observed. London: Faber \& Faber.

Margulies, A. 1989. The empathic imagination. New York: W.W. Norton \& Company.

Merleau-Ponty, M. 1945/2012. Phenomenology of perception, trans. D. Landes. London: Routledge.

Merleau-Ponty, M. 1964a. Signs, trans. R.C. McCleary. Evanston: Northwestern University Press.

Merleau-Ponty, M. 1964b. Sense and non-sense, trans. H.L. Dreyfus and P.A. Dreyfus. Evanston: Northwestern University Press.

Merleau-Ponty, M. 1973. The prose of the world, trans. J. O’Neill. Evanston: Northwestern University Press.

Minkowski, E. 1970. Lived time: Phenomenological and psychopathological studies, trans. N. Metzel. Evanston: Northwestern University Press.

Ratcliffe, M. 2015. Experiences of depression: A study in phenomenology. Oxford: Oxford University Press.

Ratcliffe, M. 2017. Real hallucinations: Psychiatric illness, intentionality, and the interpersonal world. Cambridge MA: MIT Press.

Ratcliffe, M. 2018. Empathy without simulation. In Imagination and social perspectives: Approaches from phenomenology and psychopathology, ed. M. Summa, T. Fuchs, and L. Vanzago, 199-220. London: Routledge.

Rogers, C. 1975. Empathic: An unappreciated way of being. The Counselling Psychologist 5: 2-10.

Slaby, J. 2014. Empathy's blind spot. Medicine, Healthcare and Philosophy 17: 249-258.

Spaulding, S. 2017. Cognitive empathy. In The Routledge handbook of philosophy of empathy, ed. H.L. Maibom, 13-21. London: Routledge.

Stein, E. 1989. On the problem of empathy, trans. W. Stein. Washington DC: ICS Publications.

Stueber, K.R. 2006. Rediscovering empathy: Agency, folk psychology and the human sciences. Cambridge MA: MIT Press.

Zahavi, D. 2001. Beyond empathy: Phenomenological approaches to intersubjectivity. Journal of Consciousness Studies 8 (5-7): 151-167.

Zahavi, D. 2010. Empathy, embodiment and interpersonal understanding: From Lipps to Schutz. Inquiry 53: $285-306$.

Zahavi, D. 2014. Self and other: Exploring subjectivity, empathy, and shame. Oxford: Oxford University Press.

Publisher's Note Springer Nature remains neutral with regard to jurisdictional claims in published maps and institutional affiliations. 